\title{
Thoracodorsal Artery Perforator and Superior Epigastric Artery Perforator Flaps for Volume Replacement Oncoplastic Breast Surgery
}

\author{
Dushyant Jaiswal ${ }^{1} \quad$ Prabha Subhash Yadav ${ }^{1}$ Vinay Kant Shankhdhar ${ }^{1} \quad$ Tasneem Jaffer Belgaumwala $^{1}$ \\ ${ }^{1}$ Department of Plastic and Reconstructive Surgery, Tata Memorial \\ Hospital, Homi Bhabha National Institute, Mumbai, Maharashtra, \\ India

\begin{abstract}
Address for correspondence Dushyant Jaiswal, MCh (Plastic and Recontructive Surgery), Department of Plastic and Reconstructive Surgery, Tata Memorial Hospital, Homi Bhabha National Institute, Dr. Ernest Borges Road, Mumbai 400012, Maharashtra, India (e-mail: drdushyantjaiswal@yahoo.co.in).
\end{abstract}

Indian J Plast Surg 2019;52:304-308

\begin{abstract}
Introduction Breast conservation therapy $(\mathrm{BCT})$ and oncoplastic breast surgery (OBS) are now established modalities of treatment for breast cancer, with proven oncological safety. Traditionally, latissimus dorsi (LD) flaps have been the one-stop solution workhorse when volume replacement is needed. We present our experience with thoracodorsal artery perforator (TDAP) and superior epigastric artery perforator (SEAP) flaps. These flaps allow the preservation of muscle structure and function.

Material and Methods Data were collected prospectively of patients in whom pedicled perforator flaps after BCT were used. A handheld 8-MHz audio Doppler was used

Keywords

- oncoplastic breast surgery

- volume replacement

- breast conservation therapy

- partial breast reconstruction

- perforator flaps

- TDAP

- SEAP to locate the perforators. TDAP flaps were used in four patients, whereas SEAP flaps were used in two patients. Skin paddle sizes ranged from $10 \times 3 \mathrm{~cm}$ to $21 \times 7 \mathrm{~cm}$.

Results TDAP flaps were used in four patients, whereas SEAP flaps were used in two patients All flaps survived. No flap had partial necrosis or fat necrosis. All donor sites were closed primarily and healed uneventfully, and none had a seroma requiring aspiration.

Conclusion TDAP flaps can be selectively employed when the LD muscle function needs to be preserved. SEAP flaps can also be employed as a rare option in case of lower inner quadrant defects. Pedicled perforator flaps are a useful and reliable option for volume replacement OBS in select patients for reconstructing partial mastectomy defects.
\end{abstract}

\section{Introduction}

Breast conservation therapy (BCT) and oncoplastic breast surgery (OBS) are now established modalities of treatment for breast cancer, with proven oncological safety. ${ }^{1}$ BCT involves partial breast resection, which, if left unaddressed, often leads to a cosmetic deformity. Severity of this deformity is determined by the amount of resection relative to the size of the breast and location of the tumor. OBS with volume displacement options employ principles of local flaps, mastopexy or reduction mammoplasty. OBS

received

May 8, 2019

accepted after revision

October 4, 2019

published online

December 26, 2019 with volume replacement involves adding tissue from outside the breast for partial breast defects to restore form and cosmesis. Traditionally, latissimus dorsi (LD) flaps have been the one-stop solution workhorse for these defects. ${ }^{2}$ Perforator based flaps, thoracodorsal artery perforator (TDAP) flap, lateral intercostal artery perforator flap, anterior intrercostal artery perforator (AICAP) flap, and superior epigastric artery perforator (SEAP) flap sparing the underlying muscle are the next step in the evolution. ${ }^{3}$ We present our initial experience with TDAP and SEAP flaps used for selective indications.
DOI https://doi.org/ 10.1055/s-0039-3400688 ISSN 0970-0358.
(C)2019 Association of Plastic Surgeons of India
License terms

() (1) $\ominus \circledast$ 


\section{Material and Methods}

Consecutive perforator flaps (TDAP/SEAP) for partial breast reconstruction used between January 2015 and January 2016 were included in the study. Data were stored in an MS Excel sheet, including hospital electronic medical records and personal logs of the first author. Good Doppler signal and direct visualization of a good perforator through the breast excision wound were prerequisites to proceeding with the TDAP/SEAP harvest. Magnification with $4 \times$ Loupes and microsurgical technique were used for all pedicle and perforator dissections.

As both TDAP and SEAP flaps are established flaps, as described in the literature, for partial breast reconstruction at other centers worldwide, institutional ethics committee approval was not deemed necessary.

\section{Results}

TDAP flaps were used in four patients, whereas SEAP flaps were used in two patients (-Table 1). Handheld $8-\mathrm{MHz}$ audio Doppler was used to locate the perforators. Skin paddle sizes ranged from $10 \times 3 \mathrm{~cm}$ to $21 \times 7 \mathrm{~cm}$. All donor sites were amenable to primary closure. All flaps survived. No flap had partial necrosis or fat necrosis. No donor site required repeated seroma aspiration.

\section{Cases (-Fig. 1A-H, 2A-F, 3A-I)}

\section{Discussion}

LD myocutaneous flap is the most common local flap option for reconstruction of lateral, central, and even

Table 1 Results

\begin{tabular}{|c|c|c|c|c|c|}
\hline No. & Site & Size of lesion & Axilla & Comorbidities & Previous surgery \\
\hline 1 & LIQ & $2 \mathrm{~cm}$ & No & No & No \\
\hline 2 & $\mathrm{LIQ}+\mathrm{CQ}$ & $\begin{array}{l}\text { Scar from a previous } \\
\text { surgery }\end{array}$ & No & No & Lumpectomy \\
\hline 3 & UOQ & $2 \times 1.5 \mathrm{~cm}$ & $2 \times 1 \mathrm{~cm}$ & Hypothyroid & No \\
\hline 4 & UOQ & $5.5 \times 6 \mathrm{~cm}$ & No & Diabetes & No \\
\hline 5 & LOQ & $9 \times 7 \mathrm{~cm}$ & No & Diabetes & No \\
\hline 6 & UOQ & $5 \times 6 \mathrm{~cm}$ & $2 \times 2 \mathrm{~cm}$ & No & Lumpectomy twice \\
\hline No. & Dimensions & Doppler & Paddle orientation & No. of perforators & Nerve preserved \\
\hline 1 & $10 \times 3 \mathrm{~cm}$ & Yes & Oblique & 1 & NA \\
\hline 2 & $15 \times 6.5 \mathrm{~cm}$ & Yes & Vertical & 1 & NA \\
\hline 3 & $21 \times 7 \mathrm{~cm}$ & Yes & Transverse & 1 & Yes \\
\hline 4 & $23 \times 7.5 \mathrm{~cm}$ & Yes & Transverse & 1 & Yes \\
\hline 5 & $20 \times 8 \mathrm{~cm}$ & Yes & Transverse & 1 & Yes \\
\hline 6 & $22 \times 8 \mathrm{~cm}$ & Yes & Transverse & 1 & Yes \\
\hline No. & Donor closure & Contralateral breast & Pathology & \multicolumn{2}{|c|}{ No. of perforators } \\
\hline 1 & Primary & No & IDC & \multicolumn{2}{|l|}{1} \\
\hline 2 & Primary & No & IDC & \multicolumn{2}{|l|}{1} \\
\hline 3 & Primary & No & IDC & \multicolumn{2}{|l|}{1} \\
\hline 4 & Primary & No & IDC & \multicolumn{2}{|l|}{1} \\
\hline 5 & Primary & Reduction & $\begin{array}{l}\text { Malignant phyllodes } \\
\text { tumor }\end{array}$ & \multicolumn{2}{|l|}{1} \\
\hline 6 & Primary & No & IDC & \multicolumn{2}{|l|}{1} \\
\hline No. & Port & Late complications & Fat necrosis & Lymphedema & \\
\hline 1 & Yes & No & No & No & No \\
\hline 2 & Yes & No & No & No & No \\
\hline 3 & Yes & No & $\mathrm{No}$ & No & No \\
\hline 4 & Yes & Post RT breast abscess & No & No & Distant metastasis, deceased \\
\hline 5 & No & No & No & No & No \\
\hline 6 & Yes & No & No & No & No \\
\hline
\end{tabular}

Abbreviations: CQ, central quadrant; IDC, inflammatory ductal carcinoma; LIQ, lower inner quadrant; LOQ, lower outer quadrant; NA, not applicable; $\mathrm{RT}$, radiotherapy; UOQ, upper outer quadrant. 

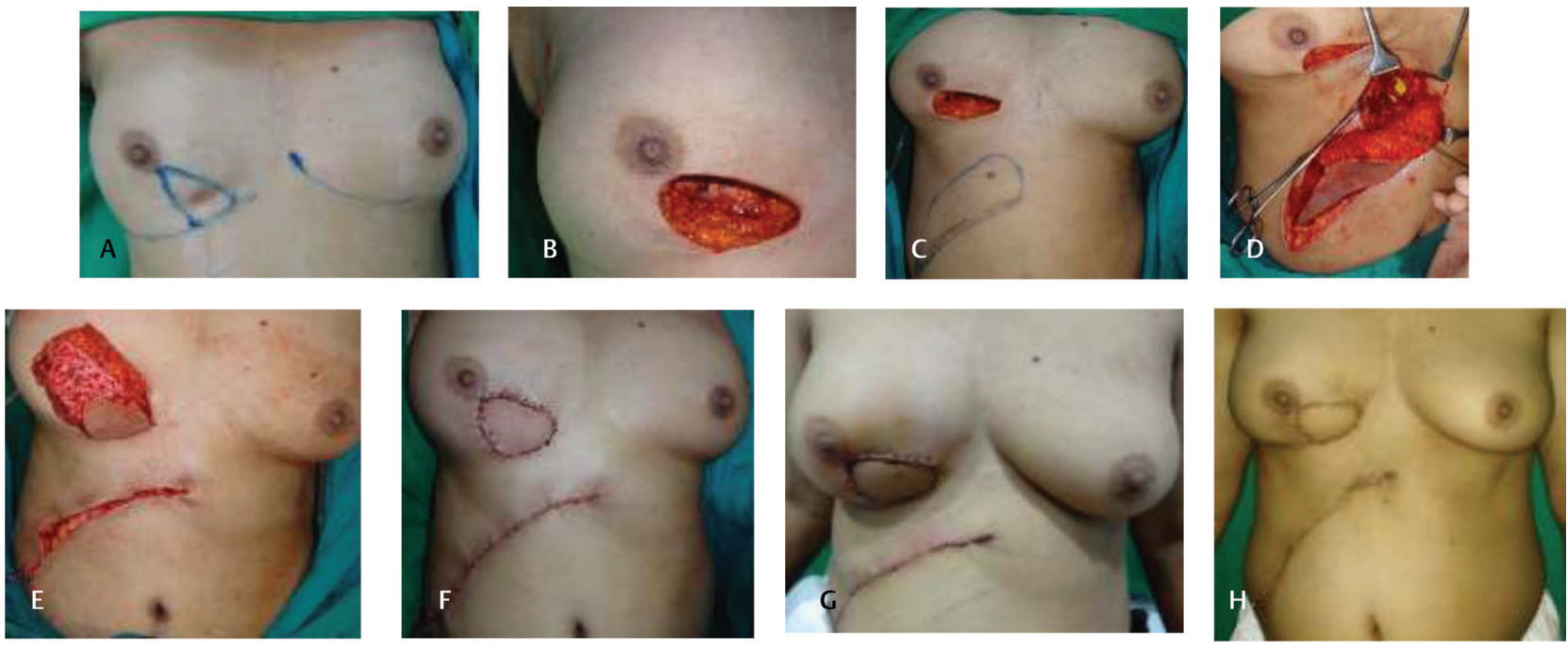

Fig. 1 (A) A 55-year-female, postneoadjuvant chemotherapy, previous cholecystectomy scar present. (B) Postexcision defect in the lower inner quadrant. (C) Doppler marking of the perforator, with the flap planned around it. (D) Flap raised, showing a superior epigastric artery perforator. (E) Good bleeding after flap transposition; the donor site was closed primarily. (F) Immediate postoperative result. (G) Late postoperative result. (H) Postradiotherapy result; bilateral breast symmetry is maintained.
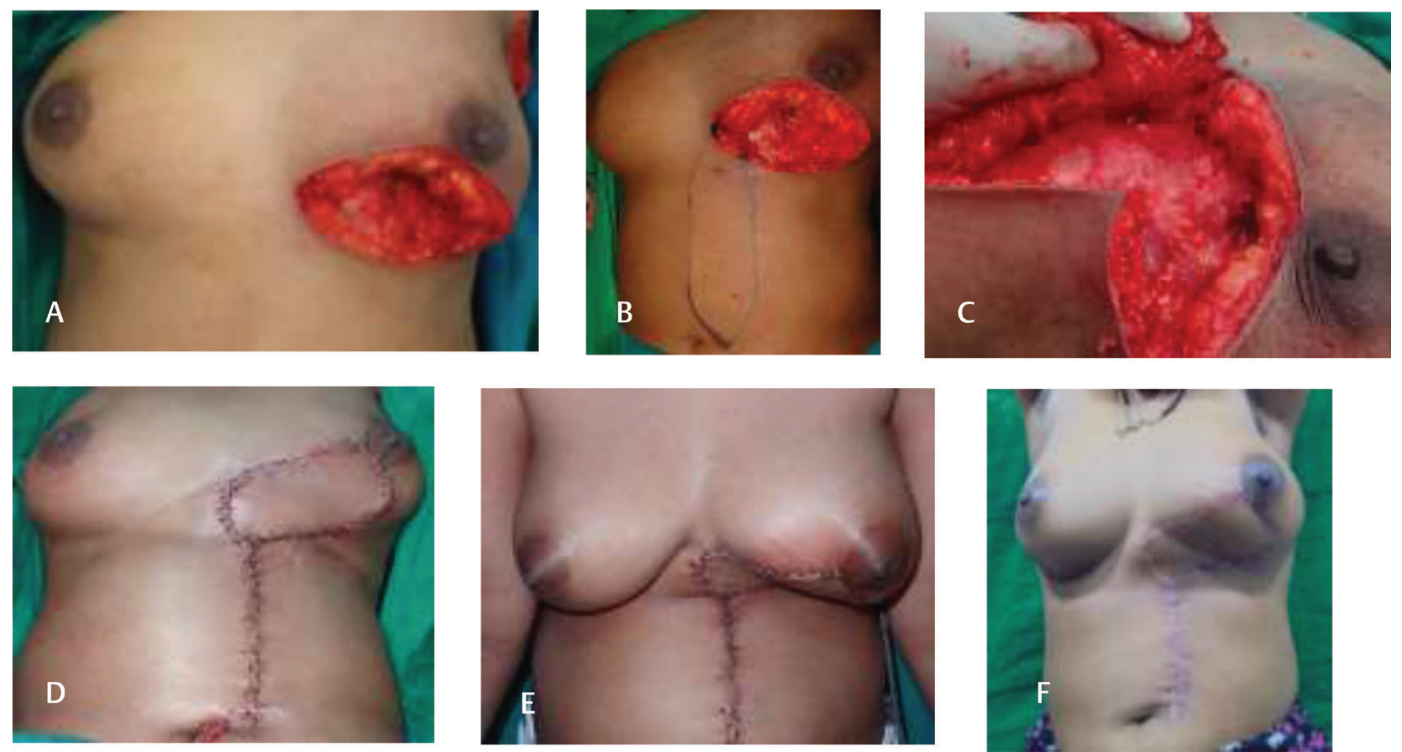

Fig. 2 (A) A 41-year-female with a defect in the lower inner and lower central quadrant and inadvertent injury to thoracodorsal artery and vein during axillary dissection. (B) Doppler marking of the perforator, with the flap planned around it. (C) Flap raised, showing a superior epigastric artery perforator. (D) After flap inset, the donor site was closed primarily. (E) Immediate postoperative result. (F) Late postoperative result.

medial defects following BCT. ${ }^{4}$ The disadvantages are donor-site morbidity and postradiotherapy muscle atrophy resulting in asymmetry. ${ }^{5-9} \mathrm{~A}$ less frequently exercised option using the same donor site is the TDAP flap. The thoracodorsal artery originates from the subscapular axis and courses along the deep surface of the muscle for some distance before dividing into its muscular (transverse and vertical/lateral) branches. These branches pierce the muscle at an angle of approximately 45 degrees to one another and travel through the muscle for a variable distance giving off intramuscular branches before they finally pierce the fascia to supply the subcutaneous fat and overlying skin through a series of perforators. ${ }^{10}$ Cadaver dissections performed in various studies quote a range of one to nine cutaneous perforators, with the largest and most consistent being the first one that is located approximately 6 to $10 \mathrm{~cm}$ from the axilla and 1 to $4 \mathrm{~cm}$ medial to the lateral free border of the muscle. ${ }^{11-16}$

More than one perforator can be included if they are in the same longitudinal plane, but it would mean the sacrifice of intervening muscle fibers and might restrict the reach. Careful separation of the thoracodorsal nerve is performed until the desired pedicle length is achieved. Advantages of the TDAP flap include decreased loss of muscle function, lesser distortion of back contour, and less postoperative pain and seroma formation. ${ }^{14,17}$ Depending on the position of the perforator, TDAP flap 

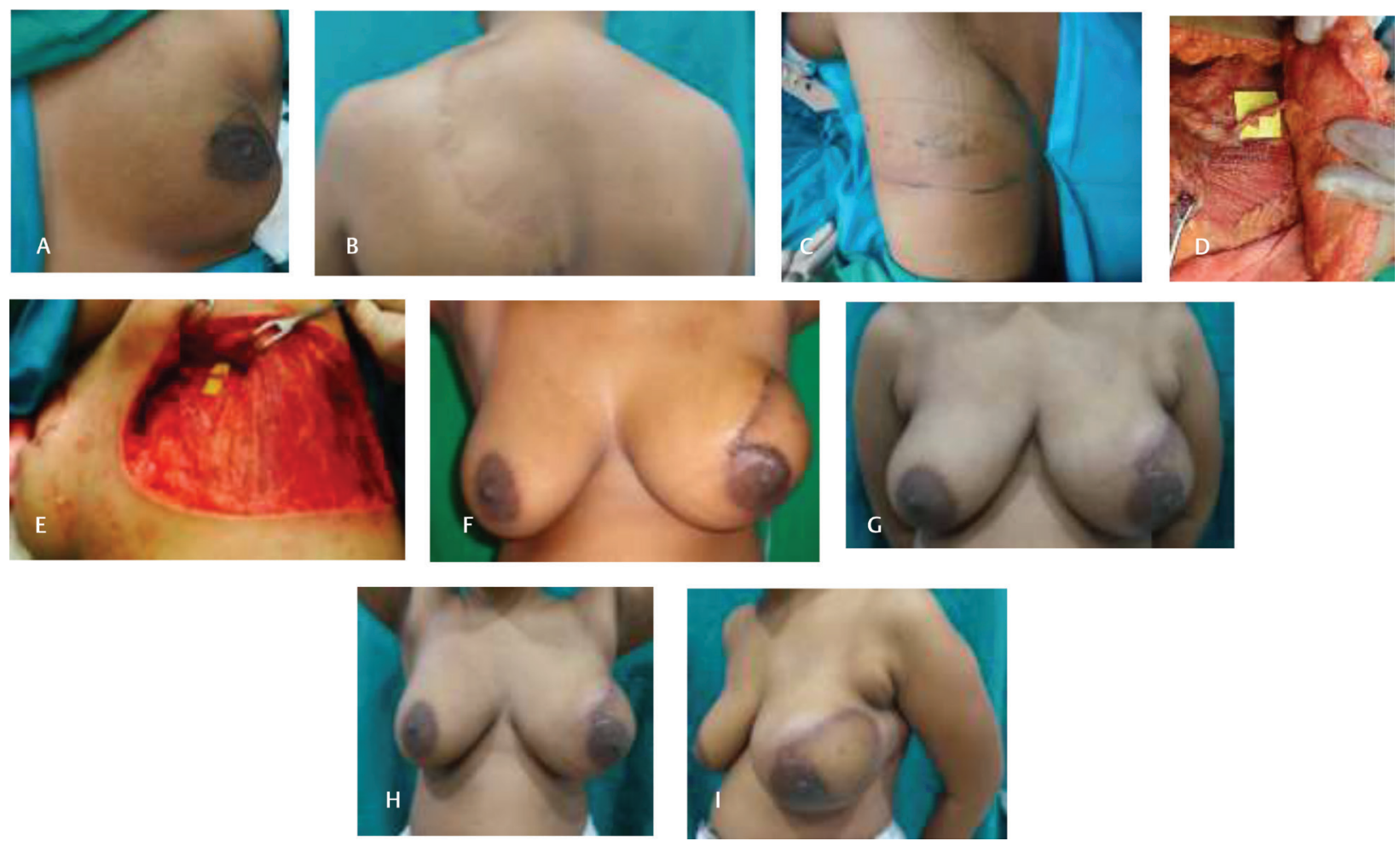

Fig. 3 (A) A 36-year-female with proposed excision in the upper outer quadrant. (B) Scar from a previous spinal surgery; the patient is dependent on a crutch. (C) Doppler marking of the perforator, with the flap planned around it. (D) Flap raised, showing a thoracodorsal perforator. (E) The preserved thoracodorsal nerve and muscle after flap harvest. (F) Immediate postoperative result. (G-I) Late postoperative result.

is amenable for the coverage of the upper outer, central, and lower outer quadrant defects. The reach for defects in the inner quadrant might be less and will depend on the length of available perforator and pedicle. A modified version of this flap, described as the extended TDAP flap, has been described by Angrigiani et al for larger volume breast reconstruction (including whole breast reconstruction) and coverage of implant. ${ }^{18}$

The other options for lower inner quadrant breast defects are AICAP ${ }^{19}$ and SEAP flaps. The superior epigastric vessels run superficial to the posterior rectus sheath and deep to the rectus abdominis muscle before they penetrate the muscle caudal to the xiphoid process and reach the skin. There are four to six SEAPs that supply 110 to $190 \mathrm{~cm}^{1}$ of the upper abdominal area. ${ }^{3}$ The perforators with a caliber of $>0.5 \mathrm{~mm}$ are found most frequently in an area 2 to $6 \mathrm{~cm}$ from the midline and 0 to $10 \mathrm{~cm}$ below the xiphoid process. ${ }^{1}$ The location of perforators is identified preoperatively using a handheld Doppler. Multidetector computed tomography (MDCT) could be used for a selective localization of perforators, particularly in salvage cases in which perforators could be injured during abdominal skin undermining or a previous axillary dissection. ${ }^{20,21}$

The extent of the flap is dependent on the location of the perforators. A safe length of a perforator flap depends on many factors such as perforator diameter, location, and orientation in the soft tissue. ${ }^{2}$ In a transversely designed flap, the flap's length-to-width ratio should be 1:2.5 or less, and a safe lateral limit of the flap is the posterior axillary line. ${ }^{22}$ According to Hamdi et al, the zone lateral to the anterior axillary line is mainly supplied by the posterior intercostal arteries, and this is the zone that has contributes to flap tip necrosis in transversely designed flaps. ${ }^{21}$ In our case, the flap was extended up to the anterior axillary line without distal necrosis. Vertical SEAP flaps can be extended safely up to the level of the umbilicus. ${ }^{2}$ According to Hamdi et al and Uemura, the zone below the midpoint between the xiphoid process and the umbilicus is supplied primarily by the deep inferior epigastric artery perforator, which contributes to tip necrosis in the vertical SEAP flap. ${ }^{12,23}$ Distal flap necrosis should be considered while planning a SEAP flap, especially in vertically oriented flaps, because of more proximal perforators, or venous congestion, possibly due to imbalanced choke vessel communication..$^{21,24} \mathrm{~A}$ vertical flap design might be safer for more caudally located perforators or a reduced vertical flap length. ${ }^{2}$ We raised a vertical flap up to the level of umbilicus without any distal flap necrosis. The factors that are considered to be important while raising an SEAP flap are location of the defect, size of the defect relative to breast size, location of the perforators, design of flap, and length of the flap. In the first patient, a transverse skin paddle was designed as the defect was small and the patient already had a preexisting cholecystectomy scar. We designed the flap around it, recruiting the abdominal skin for closure, thus retaining the inframammary fold (IMF) in place. There was no breach in the IMF except in the area of flap transfer. The closure was not tight either. There was no change in the position of the IMF as observed at the 6 months postcompletion of the radiotherapy visit. 
The second patient was planned for a vertically designed flap as the defect was large and perforators were identified caudally. The defect was close to the IMF, and a horizontal scar would have interfered with the donor closure or pulled the breast in the abdomen.

Advantages of the SEAP flap are longer pedicle, relative ease of flap harvest, and no donor-site morbidity. Intact SEA following perforator flap maintains the future use of the rectus abdominis flap for breast reconstruction, ${ }^{2}$ as the source vessel is spared. ${ }^{20}$

Intercostal artery perforator flap is based on perforators originating from the intercostal vessels through the rectus abdominis or the external oblique muscles, but it has a short pedicle. ${ }^{19,25}$

Microsurgical flaps for partial breast reconstruction are an option, but for flap harvest, donor sites from anywhere would leave a scar. Free groin or free superficial inferior epigastric artery perforator flaps would give the best donor site appearance, but the volume of fat available is limited. Anterolateral thigh, transverse upper gracilis, or lateral thigh flaps are the other flaps described for partial breast reconstruction, but all of them come with a scar not better concealed than a back scar. DIEP flap from the abdomen would be too bulky, probably an overkill, for a partial breast defect, and a resource for whole breast reconstruction in case of recurrence. All free flaps would also need microvascular surgery, adding time and cost.

\section{Conclusion}

TDAP flap can be selectively employed when LD muscle function needs to be preserved and a smaller flap is desired. SEAP can also be employed as a rare option in case of lower inner quadrant defects. Pedicled perforator flaps are a useful and reliable option for volume replacement OBS in select patients for reconstructing partial mastectomy defects.

\section{Conflict of Interest}

None.

\section{References}

1 Schmidt M, Tinhofer I, Duscher D, Huemer GM. Perforasomes of the upper abdomen: an anatomical study. J Plast Reconstr Aesthet Surg 2014;67(1):42-47

2 Hamdi M, Craggs B, Stoel AM, Hendrickx B, Zeltzer A. Superior epigastric artery perforator flap: anatomy, clinical applications, and review of literature. J Reconstr Microsurg 2014;30(7):475-482

3 Offman SL, Geddes CR, Tang M, Morris SF. The vascular basis of perforator flaps based on the source arteries of the lateral lumbar region. Plast Reconstr Surg 2005;115(6):1651-1659

4 Munhoz AM, Montag E, Fels KW, et al. Outcome analysis of breast-conservation surgery and immediate latissimus dorsi flap reconstruction in patients with $\mathrm{T} 1$ to $\mathrm{T} 2$ breast cancer. Plast Reconstr Surg 2005;116(3):741-752

5 Spear SL, Hess CL. A review of the biomechanical and functional changes in the shoulder following transfer of the latissimus dorsi muscles. Plast Reconstr Surg 2005;115(7):2070-2073
6 Adams WP, Jr, Lipschitz AH, Ansari M, Kenkel JM, Rohrich RJ. Functional donor site morbidity following latissimus dorsi muscle flap transfer. Ann Plast Surg 2004;53(1):6-11

7 Clough KB, Louis-Sylvestre C, Fitoussi A. Couturaud B, Nos C. Donor site sequelae after autologous breast reconstruction with an extended latissimus dorsi flap. Plast Reconstr Surg 2002;109(6):1904-1911

8 Russell RC, Pribaz J, Zook EG, Leighton WD, Eriksson E, Smith CJ. Functional evaluation of latissimus dorsi donor site. Plast Reconstr Surg 1986;78(3):336-344

9 Schwabegger A, Ninković M, Brenner E, Anderl H. Seroma as a common donor site morbidity after harvesting the latissimus dorsi flap: observations on cause and prevention. Ann Plast Surg 1997;38(6):594-597

10 Haq EU, Javaid RH, Hameed S, et al. Thoracodorsal artery perforator flap for upper limb reconstruction. J Ayub Med Coll Abbottabad 2015;27(2):451-457

11 Angrigiani C, Grilli D, Siebert J. Latissimus dorsi musculocutaneous flap without muscle. Plast Reconstr Surg 1995;96(7):1608-1614

12 Thomas BP, Geddes CR, Tang M, Williams J, Morris SF. The vascular basis of the thoracodorsal artery perforator flap. Plast Reconstr Surg 2005;116(3):818-822

13 Rowsell AR, Davies DM, Eisenberg N, Taylor GI. The anatomy of the subscapular-thoracodorsal arterial system: study of 100 cadaver dissections. Br J Plast Surg 1984;37(4):574-576

14 Guerra AB, Metzinger SE, Lund KM, Cooper MM, Allen RJ, Dupin CL. The thoracodorsal artery perforator flap: clinical experience and anatomic study with emphasis on harvest techniques. Plast Reconstr Surg 2004;114(1):32-41

15 Heitmann C, Guerra A, Metzinger SW, Levin LS, Allen RJ. The thoracodorsal artery perforator flap: anatomic basis and clinical application. Ann Plast Surg 2003;51(1):23-29

16 Tansatit T, Chokrungvaranont P, Wanidchaphloi S, Sanguansit P. The anatomy of the thoracodorsal artery in perforator flap for resurfacing shallow defect. J Med Assoc Thai 2007;90(5):947-955

17 Titley OG, Spyrou GE, Fatah MF. Preventing seroma in the latissimus dorsi flap donor site. Br J Plast Surg 1997;50(2):106-108

18 Angrigiani C, Rancati A, Escudero E, Artero G. Extended thoracodorsal artery perforator flap for breast reconstruction. Gland Surg 2015;4(6):519-527

19 Hamdi M, Van Landuyt K, de Frene B, Roche N, Blondeel P, Monstrey $S$. The versatility of the inter-costal artery perforator (ICAP) flaps. J Plast Reconstr Aesthet Surg 2006;59(6):644-652

20 Masia J, Clavero JA, Larrañaga JR, Alomar X, Pons G, Serret P. Multidetector-row computed tomography in the planning of abdominal perforator flaps. J Plast Reconstr Aesthet Surg 2006;59(6):594-599

21 Hamdi M, Van Landuyt K, Ulens S, Van Hedent E, Roche N, Monstrey S. Clinical applications of the superior epigastric artery perforator (SEAP) flap: anatomical studies and preoperative perforator mapping with multidetector CT. J Plast Reconstr Aesthet Surg 2009;62(9):1127-1134

22 Tai Y, Hasegawa H. A transverse abdominal flap for reconstruction after radical operations for recurrent breast cancer. Plast Reconstr Surg 1974;53(1):52-54

23 Uemura T. Superior epigastric artery perforator flap: preliminary report. Plast Reconstr Surg 2007;120(1):1e-5e

24 Mah E, Rozen WM, Ashton MW, Flood S. Deep superior epigastric artery perforators: anatomical study and clinical application in sternal reconstruction. Plast Reconstr Surg 2009;123(6):1719-1723

25 Losken A, Hamdi M. Partial breast reconstruction: current perspectives. Plast Reconstr Surg 2009;124(3):722-736 